\title{
Specification and Misconception About COVID-19 Disappearing
}

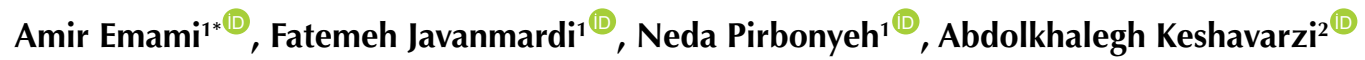 \\ ${ }^{1}$ Microbiology Department, Burn and Wound Healing Research Center, Shiraz University of Medical Sciences, Shiraz, Iran. \\ ${ }^{2}$ Surgery Department, General Surgery Burn and Wound Healing Research Center, Shiraz University of Medical Sciences, \\ Shiraz, Iran.
}

*Correspondence to Amir Emami, Microbiology Department, Burn and Wound Healing Research Center, Shiraz University of Medical Sciences, Shiraz Iran. Tel: +98-71-3230 5884, Email: emami.microbia@gmail.com

Received April 20, 2020 Accepted April 29, 2020 Published online March 31, 2020

\begin{abstract}
Dear Editor,
Coronavirus disease 2019 (COVID-19) is a respiratory disease which is caused by severe acute respiratory syndrome coronavirus-2 (SARS-CoV-2). This virus was first detected in Wuhan, Hubei, China, in December 2019, and was named as a pandemic disease by the World Health Organization (WHO) on March 11, 2020. In March 21, 2020 , the confirmed cases of COVID-19 increased to more than 303000 in over 187 countries and territories around the world. Based on published reports, major outbreaks ( $>20000$ cases) have been reported in mainland China, Italy, Spain, USA, Germany, and Iran, respectively. SARS-CoV-2 is a member of the family Coronaviridae. This RNA-containing virus is an enveloped virion with a positive-sense, single-stranded genome. Structurally coronavirus virions are spherical, approximately 50-200 $\mathrm{nm}$ in diameter, with the prominent feature of club-shaped spikes on the surface of the virion. ${ }^{1}$ This virus has caused three epidemic respiratory diseases in the 21st century from which the lately introduced one (SARS-CoV-2) has massively spread and become prevalent around the world. This novel coronavirus has had a remarkable effect on health and economic systems of countries. Although the precise mode of transmission of this virus is unclear, some transmission routs like spreading by droplets, touching the face after a close direct or indirect contact with confirmed cases, touching the contaminated surfaces with hands are presumed. Based on some limited studies, it has been declared that SARS-CoV-2 may stay in aerosols for hours and on surfaces for days. ${ }^{2}$ This is while in new research published in The New England Journal of Medicine it has been mentioned that half-life of SARS-CoV-2 in aerosols is similar to that of SARS-CoV-1 and is estimated about
\end{abstract}

1.1 to 1.2 hours with $95 \%$ confidence intervals. ${ }^{3}$ Two points about this virus are very important in comparison with other members of the Coronaviridae family: (1) it has a higher transmission power (R0: reproduction number of roughly 2 to 3 ), and (2) it has a longer incubation period (median from 5 to 6 -12 days, with a range from one to up to 14 days) than other respiratory viral infections, and is highly contagious during this period. ${ }^{4,5}$ Due to the high similarity of this novel coronavirus with other SARS-like coronaviruses $(>88 \%)$, this assumption is formed that the viability of this new virus is similar to that of other members of this family, however, some evidence denies this (i.e., it is widespread). Owing to the global outbreak of COVID-19, one of the great points about controlling the SARS-CoV-2 is having information about the propagation power and how to control and destroy it in the environment and human population. According to the documents, some viruses of family Coronaviridae like SARS-CoV-1 become inactive at $56^{\circ} \mathrm{C}$ for 15 minutes, and when exposed to ultraviolet at $\mathrm{pH}>12$ or $<3$; however, it is stable for days following drying on plastic materials. ${ }^{6}$ This is while SARS-CoV-2 is a new infection with novel specifications and activity. ${ }^{7}$ Due to this novelty, the survival of SARS$\mathrm{CoV}-2$ in different environmental conditions such as temperature and humidity is of significant importance in understanding the persistence and transmission of the virus. Although the SARS-CoV-2 function and behavior have been determined in the environment to some extent, this issue needs further study. One of the key points about the potency of this virus is its pandemic status in the world which allows the virus to be highly adapted to various environmental conditions such as different temperatures and humidity. Moreover, it has been shown that SARS- 
CoV-2 can drive different clinical behaviors in an acute lethal form, in a mild and asymptomatic manner. ${ }^{8}$ One of the reasons that has led researchers to announce the end of the outbreak in the warm conditions is that in warm seasons, people tend to be less present in confined spaces; this is while the most important factor in reducing the respiratory infections such as COVID-19 is to cut the link in the chain of transmission among the human population. Another documented point about this virus is that SARS-CoV-2 is spread mostly by small mucus droplets like flu viruses. Considering this, when the virus is present in the environment, based on the conditions (material, temperature, and humidity), they lose their infectivity in result of the loss of structural integrity of the particles. Although the flu viruses like influenza viruses are more dangerous (36 million illnesses, 370000 hospitalizations and 22000 deaths in recent year in America based on the Centers for Disease Control and Prevention (CDC) reports) compared to the new coronavirus outbreak, scientists have studied seasonal flu for decades, and we know a lot about flu viruses and what to expect each season, and this is while COVID-19 is something of a wild card in terms of how far it will spread, outbreak patterns, its high risks, and how many deaths it will cause. Due to the high molecular mass of SARS-CoV-2, environmental surfaces play an important role in the transmission of the virus infections; then knowing the viability of SARS-CoV-2 on surfaces may be helpful in the management and control of COVID-19 infection in the community especially that this knowledge plays an important role in controlling the spread of nosocomial viral infections during the global outbreak of this novel virus. Although the viability of SARS-CoV-2 on different surfaces is still not verified, according to some researches it has been declared that SARS-CoV-2 lives on copper for 4 hours and on cardboard for 1 day. This is while this virus is more stable on plastic and stainless steel for about 3 days. $^{3}$ About the stability of the virus in different temperatures and humidity conditions, it must be noted that although this virus is thermolabile, the increase of relative humidity substantially lowers the virus transmission. It can live on feces for 24 to 48 hours at room temperature. Heat $\left(56^{\circ} \mathrm{C}\right)$ inactivates SARS coronavirus in 30 minutes, $70^{\circ} \mathrm{C}$ in 5 minutes, $37^{\circ} \mathrm{C}$ in 2 days, and $22^{\circ} \mathrm{C}$ in 14 days. Even in some other related studies, it has been reported that one-unit increase in temperature and absolute humidity reduces SARS-CoV-2 viability by lag 3 and lag 5, respectively. ${ }^{9}$ In some reports of the WHO, it has been mentioned that coronaviruses are very stable in the frozen states generally as they survive for up to two years at $-20^{\circ} \mathrm{C}$. Although there is no specific information about SARS-CoV-2 thermal stability, it has been proved that MERS-CoV can remain viable for up to 72 hours at refrigerator temperature $\left(4^{\circ} \mathrm{C}\right)$. In this regard, checking the food hygiene and good food safety practices can prevent their transmission through food. Accordingly, it should be noted that this virus is susceptible to normal cooking temperatures $\left(70^{\circ} \mathrm{C}\right)$ and will be inactive and destroyed in well-cooked foods. ${ }^{10}$

Based on the lack of knowledge about SARS-CoV-2, and the fact that there is yet no specific treatment or vaccine, a strong public health surveillance system is required and efficient diagnostic and quarantine policies should be applied. Furthermore, governments, public health authorities, and health care providers should cooperate with each other in this respect. It is worth to note that if COVID-19 is not controlled until winter or cold seasons, its coincidings with other respiratory diseases such as influenza will complicate the outbreak of respiratory infections in the world with an increase in morbidity and mortality of infected patients and we will be facing a growing burden of health problems around the world.

\section{Conclusion}

In conclusion, it is highly recommended that the recent disaster is prevented and controlled in such a way that the lowest mortality rate and related costs are endured. Such an aim could be reached provided that sanitation and personal hygiene is well observed. The following guidelines in two steps are recommended:

First: Personal guidelines: 1. Wash the hands by rubbing them with an alcohol-based formulation frequently, 2. Avoid touching the face with dirty hands, 3. No handshaking during the outbreak, 4. Keep social distancing, 5. Follow the cough or sneeze etiquette (covering mouth/nose with the bent elbow or tissue), 6 . Stay at home if you begin to feel unwell, even with mild symptoms, 7. Although it is not necessary for healthy individuals, the use of mask by general population can reduce the risk of aerosol transmission in indoor populated environments.

Second: Social and environmental guidelines: 1. Avoid consumption of raw or undercooked animal products, 2. Handle raw animal and dairy products with care, 3. Disinfect items that are frequently touched throughout the day, 4. Isolation and quarantine of patients confirmed positive, 5 . Discard correctly the masks, gloves, and so on used by patients or their caregivers (in buckets), 6. Avoid unnecessary travels during the virus epidemic or if you have a fever or a dry cough, 7 . Avoid spiting.

\section{Ethical Approval}

Not applicable.

\section{Conflict of Interest Disclosure}

None.

\section{References}

1. Chen N, Zhou M, Dong X, et al. Epidemiological and clinical characteristics of 99 cases of 2019 novel coronavirus pneumonia in Wuhan, China: a descriptive 
study. Lancet. 2020;395(10223):507-513. doi:10.1016/ s0140-6736(20)30211-7

2. Lewis R. Coronavirus Stays in Aerosols for Hours, on Surfaces for Days. Medscape; 2020. https://www.medscape. com/viewarticle/926929.

3. van Doremalen N, Bushmaker T, Morris DH, et al. Aerosol and surface stability of SARS-CoV-2 as compared with SARS-CoV-1. N Engl J Med. 2020;382(16):1564-1567. doi:10.1056/NEJMc2004973

4. European Centre for Disease Prevention and Control (ECDC). Novel Coronavirus Disease 2019 (COVID-19) Pandemic: Increased Transmission in the EU/EEA and the UK - Sixth Update. Stockholm: ECDC; 2020.

5. Backer JA, Klinkenberg D, Wallinga J. Incubation period of 2019 novel coronavirus (2019-nCoV) infections among travellers from Wuhan, China, 20-28 January 2020. Euro Surveill. 2020;25(5). doi:10.2807/1560-7917. es.2020.25.5.2000062
6. National Institutes of Health (NIH). New Coronavirus Stable for Hours on Surfaces SARS-CoV-2 Stability Similar to Original SARS Virus. NIH; 2020.

7. Darnell ME, Subbarao K, Feinstone SM, Taylor DR. Inactivation of the coronavirus that induces severe acute respiratory syndrome, SARS-CoV. J Virol Methods. 2004;121(1):85-91. doi:10.1016/j.jviromet.2004.06.006

8. Sajadi MM, Habibzadeh P, Vintzileos A, et al. Temperature and Latitude Analysis to Predict Potential Spread and Seasonality for COVID-19. SSRN; 2020:1-18. doi:10.2139/ ssrn.3550308

9. Ma Y, Zhao Y, Liu J, et al. Effects of temperature variation and humidity on the mortality of COVID-19 in Wuhan. medRxiv. 2020. doi:10.1101/2020.03.15.20036426

10. World Health Organization (WHO). Coronavirus Disease 2019 (COVID-19): Situation Report - 32. Geneva: WHO; 2020:1-7.

Please cite this article as follows: Emami A, Javanmardi F, Pirbonyeh N, Keshavarzi A. Specification and Misconception About COVID-19 Disappearing. Int J Basic Sci Med. 2020;5(1):1-3. doi:10.34172/ijbms.2020.01. 